\title{
DUAL EARNER FAMILY DAN PENGARUHNYA PADA KESEJAHTERAAN PSIKOLOGIS ANAK : SEBUAH STUDI LITERATUR
}

\section{DUAL-EARNER FAMILY AND ITS EFFECT ON CHILDREN'S PSYCHOLOGICAL WELL-BEING: A LITERATURE STUDY}

\author{
Tenri Pada Rustham \\ Universitas Mercubuana Yogyakarta
}

\begin{abstract}
Abstrak
Tuntutan ekonomi terkadang membuat suami (ayah) dan juga istri (ibu) dalam sebuah keluarga harus bekerja. Kondisi itu tentu saja berimplikasi positif dan juga negatif. Implikasi positif lebih pada aspek ekonomi, dan implikasi negatif lebih pada aspek psikologis keluarga, terutama pada kesejahteraan psikologis anak. Studi ini merupakan studi literatur yang mencoba menelusuri bagaimana kesejahteraan psikologis anak dengan dual earner family. Mesin pencari (search engine) digunakan sebagai alat mencari data. Hasilnya, 12 penelitian ditemukan dan digunakan sebagai sumber data. Penelitian-penelitian itu melaporkan bahwa dual earner family lebih memberikan dampak buruk bagi kesejahteraan psikologis anak, seperti mood yang buruk, depresi, kecemasan, mudah marah, agresif, sikap buruk terhadap sekolah, dan beberapa perilaku negatif lainnya. Hasil studi ini diharapkan menjadi pilot studi bagi penelitian empiris selanjutnya, terutama dalam konteks Indonesia yang bisa saja berbeda dengan temuan-temuan penelitian sebelumnya.
\end{abstract}

Kata kunci: dual earner family, kesejahteraan psikologis anak, dan studi literatur.

\begin{abstract}
Economic demands sometimes make both of the husband (father) and also the wife (mother) in a family have to work. This condition certainly has positive and negative implications. Positive implications are more on the economic aspects, and negative implications are more on the psychological aspects of the family, especially on the psychological well-being of their children. This study is a literature study that attempts to trace the condition of the psychological well-being of children in dual-earner family. Search engines are used as tools to search for data. As a result, 12 studies were found and used as data sources. These studies report that dual earner families have a more detrimental effect on a child's psychological well-being, such as bad moods, depression, anxiety, irritability, aggression, bad attitudes toward school, and several other negative behaviors. The results of this study are expected to be a pilot study for further empirical research, especially in the Indonesian context which could be different from the findings of previous studies.
\end{abstract}

Keywords: dual-earner family, children's psychological well-being, and literature studies.

\section{PENDAHULUAN}

Dual earner family saat ini telah menjadi sebuah fenomena global. Hal itu ditemukan hampir di tiap belahan dunia, tak terkecuali di Indonesia. Resesi ekonomi global, ditenggarai sebagai penyebab utama maraknya fenomena tersebut. Secara sederhana, dual earner family dapat dimakna sebagai kondisi di mana suami (ayah) dan istri (ibu) bekerja mencari nafkah (Harpell, 1984). Kondisi itu berbeda dengan traditional earner di mana hanya suami (ayah) yang bekerja mencari nafkah (Harpell, 1984). Beberapa literatur menggunakan istilah dual career familly, dual income family, atau dual worker family untuk menjelaskan hal yang sama.

Biro Ketenaga Kerjaan Amerika Serikat menyebut adanya peningkatan jumlah dual earner familly di masyarakat (2006). Di Indonesia, data tahun 2013 menunjukkan adanya peningkatan 
jumlah istri bekerja di Indonesia sekitar 56,01\%. Data lain juga menunjukkan terdapat 85,20\% keluarga yang istri dan suami bekerja (Biro Pusat Statistik, 2013). Fenomena dual earner familly di Indonesia diduga bermula sejak tahun 1997, ketika indonesia mengalami krisis ekonomi. Fakta itu sempat diulas di harian Suara Karya terbitan Desember 1997. Sejak itu, jumlah istri bekerja semakin meningkat tiap tahunnya.

Dual earner family memang memberikan dampak positif bagi peningkatan income keluarga (membantu perekenomian keluarga). Namun di sisi lain, dual earner family juga mendatangkan situasi pelik terhadap kondisi keluarga. Stewart \& Barling (1998) menyebut dual earner family dapat mempengaruhi situasi keluarga. Hal itu dapat menjadi semakin buruk jika dual earner family tersebut mempunyai anak. Zick, dkk (2001) menyatakan masalah terbesar pada keluarga dual earner adalah waktu bersama anak-anak yang kurang. Akibatnya tingkat stres dapat semakin tinggi. Smith (1992) menyebut tingkat stres dual earner family yang memiliki anak jauh lebih tinggi dibanding yang tidak mempunyai anak. Terkait itu, Christine, dkk (2010) menyebut situasi kompleks yang umumnya dialami oleh dual earner family terkait dengan urusan domestik (keluarga), seperti frekuensi konflik yang meninggi karena perdebatan tentang pengasuhan anak, pengelolaan rumah tangga, dan pengelolaan keuangan. Shimazu, dkk (2013) menemukan bahwa tingkat stres pada pasangan dalam dual earner family lebih tinggi dibanding pada pasangan traditional family. Pitrowski \& Hughes (1993) menyebut tantangan terbesar dual earner familly adalah pada bagaimana mengatur rumah tangga dan pengasuhan anak serta menjaga keharmonisan hubungan keluarga.

Fokus utama penelitian Psikologi, khususnya Psikologi Perkembangan dan Klinis Anak terkait dual earner family adalah bagaimana dampaknya terhadap kondisi psikologis anak (ZahnWaxler, dkk, 2008). Tuntutan kerja yang dapat menimbulkan stres, ditambah dengan terbatasnya waktu untuk bersama-sama dengan anak, tentu saja dapat berdampak bagi kondisi psikologis anak. Untuk itu penulis tertarik mengeskplorasi penelitian-penelitian tentang dampak psikologis anak yang berasal dari dual earner familly. Diharapkan hasil eskplorasi ini dapat menjadi pilot studi yang membuka jalan bagi para peneliti bidang Psikologi untuk melakukan penelitian empiris tentang dampak psikologis anak dengan dual earner familly, terutama dalam konteks Indonesia. Secara lebih spesifik, tujuan penelitian ini adalah untuk memberikan gambaran awal bagaimana kesejahteraan psikologis anak yang berasal dari dual earner family.

\section{METODE}

Tulisan ini merupakan studi literatur. Peneliti menggunakan mesin pencari data (search engine) untuk menelusuri penelitian-penelitian yang membahas tentang kesejahteraan psikologis anak dengan dual earner family. Dari beberapa penelitian yang diperoleh, hanya 12 jurnal penelitian yang memberikan informasi secara spesifik. 12 jurnal tersebut kemudian digunakan sebagai sumber data dalam studi ini, yaitu (pemaparan jurnal diurut berdasarkan tahun terbit): 
1. Yang pertama adalah penelitian Shimazu, A. dkk. tahun 2013, yang berjudul Work-tofamily Conflict and Family-to-work Conflict among Japanese Dual-earner Couples with Preschool Children: A Spillover-Crossover Perspective, yang diterbitkan dalam Journal of Occupational Health.

2. Yang kedua adalah penelitian Tisdale, S., \& Pitt-Catsouphes, M. tahun 2012, yang berjudul Linking Social Environments with The Wellbeing of Adolescents in Dual-Earner Families, yang diterbitkan dalam Journal Youth \& Society.

3. Yang ketiga adalah penelitian Christine, W, S., Oktorina, M \& Mula, I. tahun 2010, yang berjudul Pengaruh Konflik Pekerjaan dan Konflik Keluarga terhadap Kinerja dengan Konflik Pekerjaan Keluarga sebagai Intervening Variabel (Studi pada Dual Career Couple di Jabodetabek), yang diterbitkan dalam Jurnal Manajemen dan Kewirausahaan.

4. Yang keempat adalah penelitian Zahn-Waxler, C., Shirtcliff, E. A. \& Marceau, K. tahun 2008, yang berjudul Disorders of Childhood and 121 Adolescence: Gender and Psychopathology, yang diterbitkan dalam Annual Review of Clinical Psychology.

5. Yang kelima adalah penelitian Matjasko, J. L., \& Feldman, A. F. tahun 2006, yang berjudul Bringing Work Home: The Emotional Experiences of Mothers and Fathers, yang diterbitkan dalam Journal of Family Psychology.

6. Yang keenam adalah penelitian Vandewater, E.A., \& Lansford, J.E. tahun 2005, yang berjudul A Family Process Model of Problem Behaviors in Adolescents, yang diterbitkan dalam Journal of Marriage and Family.

7. Yang ketujuh adalah penelitian Allen, T. D., Herst, D. E., Bruck, C. S. \& Sutton, M. tahun 2000, yang berjudul Consequences Associated with Work-to-Family Conflict: A Review and Genda for Future Research, yang diterbitkan dalam Journal of Occupational Health Psychology.

8. Yang kedelapan adalah penelitian Unger, D.G., Brown, M.B., Tressell, P.A., \& Ellis McLeod, L. tahun 2000, yang berjudul Interparental Conflict and Adolescent Depressed Mood: The Role of Family Functioning, yang diterbitkan dalam Journal Child Psychiatry and Human Development.

9. Yang kesembilan adalah penelitian Frone, M. R. tahun 2000, yang berjudul Work-family Conflict and Employee Psychiatric Disorders: The National Co-morbidity Survey, yang diterbitkan dalam Journal of Applied Psychology.

10. Yang kesepuluh adalah penelitian Crouter, A.C., Bumpus, M.F., Maguire, M.C., \& McHale, S.M. tahun 1999, yang berjudul Linking Parents' Work Pressure and Adolescents' Well-Being: Insights into Dynamics in Dual-Earner Families, yang diterbitkan dalam Developmental Psychology. 
11. Yang kesebelas adalah penelitian Parcel, T.L., \& Menaghan, E.G. tahun 1994, yang berjdul. Early Parental Work, Family Social Capital, and Early Childhood Outcomes, yang diterbitkan dalam American Journal of Sociology.

12. Yang keduabelas adalah penelitian Smith, C, R. tahun 1992, yang berjudul Trends and Directions in Dual-Career Family Research, yang diterbitkan dalam Women in Management Review.

Keduabelas jurnal tersebut menyajikan informasi yang sangat beragam terkait dual earner family. Namun sesuai dengan tujuan penelitian, hanya informasi yang membahas tentang kesejahteraan psikologis anak saja yang diambil, dalam hal ini ialah terkait dampak psikologis dan faktor-faktor yang mempengaruhi dampak tersebut.

\section{HASIL DAN PEMBAHASAN}

\section{Dual earner family dan kesejahteraan psikologis anak: dampak dan faktor penyebab.}

Berdasarkan kajian jurnal diperoleh beberapa poin penting terkait kesejahteraan psikologis anak yang berasal dari dual earner family. Dua di antaranya yang paling menonjol ialah tentang dampak psikologisnya pada anak, dan faktor-faktor apa yang menyebabkannya. Berikut uraiannya:

Menurut Kinnunen \& Mouno (2001) mengatakan bahwa dual earner family berdampak pada kecendrungan anak memiliki sikap yang buruk terhadap sekolah dan menunjukkan peningkatan perilaku yang buruk seperti marah. Tisdale \& Pitt-Catshoupes (2012) ibu yang bekerja akan mempenagruhi kondisi psikologis anak seperti anak akan mudah meniru perilaku marah yang ditampakkan oleh ibu sepulang kerja, sehingga anak juga jadi pemarah. Tecvmuan Davis, sejalan dengan temuan Matjasko \& Feldman (2008) juga mengatakan hal yang sama, jika dual earner family sangat mempengaruhi kepribadian seorang, anak, menjadi suka melawan dan pemarah akan menjadi anak yang lebih agresif dan tidak ada kepedulian pada dirinya. Wierda-Boor \& Ronka (2004) menemukan bahwa anak dengan keadaan yang dual earner family ikut mempengaruhi kondisi anak menjadi mudah depresi dan menunjukkan sikap yang negative di sekolahnya.

Selanjutnya para peneliti mengemukakan bahwa dampak yang ditimbulkan oleh dual earner family lebih banyak disebabkan karena sikap orang tua yang ditampakkan pada anaknya adalah cenderung buruk. Seperti yang disampaikan oleh Kinnunen \& Mouno (2001) bahwa anak yang menemukan orang tuanya, terutama ibunya, pulang kerja dalam kondisi mood yang buruk (bad mood) cenderung mempunyai sikap yang buruk terhadap sekolah dan menunjukkan peningkatan perilaku yang buruk, seperti mudah marah. Tisdale \& Pitt-Catshoupes (2012) menemukan bahwa mood orang tua, terutama ibu, sepulang bekerja, secara langsung mempengaruhi kondisi psikologis anak. Jika ibunya pulang dalam kondisi marah, maka anak akan ikut marah, sebaliknya jika pulang dalam kondisi senang, maka anak pun ikut merasa senang.

Tecvmuan Davis, sejalan dengan temuan Matjasko \& Feldman (2008) yang menemukan bahwa ibu yang pulang bekerja dalam kondisi sedang stres (mood yang buruk) secara langsung 
dapat pindah ke anaknya. Ibu yang sedang dalam kondisi bahagia dan marah sepulang kerja berpengaruh secara langsung pada kebahagiaan dan kemarahan pada anak. Wierda-Boor \& Ronka (2004) juga menemukan persepsi anak terhadap mood orang tua, terutama ibu sepulang bekerja, berasosiasi dengan depresi dan sikap negatif anak terhadap sekolahnya.

Dalam dual earner family, ketidak berfungsian keluarga adalah salah satu dampak yang dapat ditimbulkan. Hal itu umumya disebabkan kegagalan orang tua memanajemen stres kerja yang diperoleh di kantor atau tempat kerja. Unger, dkk (2000) menyebut persepsi anak terhadap keberfungsian dan kohesifitas keluarga berkorelasi dengan depresi pada anak dan berbagai perilaku maladaptif lainnya, seperti mudah marah, agresif, melanggar aturan, dan sebagainya. Vandewater \& Lansford (2005) juga menemukan bahwa keluarga disfungsional yang sering berkonflik dapat menghasilkan anak dengan berbagai perilaku maladaptif, seperti agresif, tidak patuh, mencuri, bahkan merusak properti umum. Di sisi lan, keharmonisan keluarga, yang ditandai dengan positifnya relasi antara orang tua dengan anak, berbanding lurus dengan munculnya berbagai kondisi-kondisi positif pada anak, seperti lebih penurut, tidak agresif, dan prestasi akademik yang bagus. Frone (2000) menemukan adanya relasi yang kuat antara ketidak berfungsian keluarga dengan meningkatnya kecemasan dan gangguan mood, baik pada ke dua orang tua, maupun pada anak. Studi meta analisis yang dilakukan oleh Allen, dkk (2000) menemukan bahwa kasus depresi cenderung meningkat pada dual eraner family yang tidak fungsional. Davis (2008) menyebut, dalam dual earner family, ibu merupakan kunci utama kebahagiaan anak. Melalui penelitiannya, Davis menemukan bahwa mood ibu dapat dengan mudah tertransmisikan kepada anak.

Penelitian tentang dampak psikologis anak dengan dual earner familly telah banyak dilakukan, terutama di luar Indonesia. Pendekatannya pun beragam, baik itu kuantitatif maupun kualitatif. Subjek yang menjadi fokus dalam kajian dual earner familly dan kesejahteraan psikologis anak adalah relasi ibu dan anak, melebihi relasi ayah dan anak. Hal ini dapat dipahami karena secara tradisional, ibu adalah care giver (pengasuh anak), dan bukan bread winner (pencari nafkah). Sementara pada ayah kondisi itu tidak ditemukan. Parcel \& Menaghan (1994) menyatakan bahwa dibandingkan ayah, ibu bekerja dilaporkan lebih mudah mengalami stres dan merasa tidak puas dengan perannya sebagai ibu (care giver).

Crouter, dkk (1999) melalui penelitiannya menemukan adanya koneksi antara tekanan pekerjaan yang dirasakan orang tua dengan penyesuaian psikologis pada anak. Penelitian itu juga melaporkan bahwa tekanan pekerjaan dan kesejahteraan psikologis anak dimediasi oleh peran orang tua yang berlebih (overload), terutama pada ibu yang berperan sebagai care giver dan bread winner. Voydanoff (2004) menemukan bahwa dalam dual earner familly, konflik peran atau peran yang berlebih merupakan prediktor terhadap turunnya kesejahteraan psikologis anak yang menentukan peningkatan perilaku negatif pada anak.

Dari pemaparan diatas maka terlihat dual earner family memiliki dampak terhadap kesejahteraan psikologis anak bahkan juga berimplikasi pada kebahagiaan keluarga salah satunya 
hubungan antara pasangan. Meski Dual earner family secara ekonomi dapat meningkatkan finansial keluarga, kaya dari sisi materi, namun kurang dalam waktu. Dual earner family yang berlaku dalam keluarga akan sangat dibatasi waktu untuk dapat berkumpul dengan keluarga terutama anak, yang akhirnya akan dapat merusak perkembangan emosi dan perilaku anak.

Pemaparan diatas cukup memberikan gambaran akan besarnya dampak yang ditimbulkan dual earner family terhadap kesejahteraan psikologis anak. Kondisi ini jelas memberikan manfaat praktis bagi pihak yang terkait dalam tulisan ini berupa pentingnya peran orang tua dalam perkembangan emosi dan perilaku anak.

\section{KESIMPULAN}

Ada beberapa hal yang dapat disimpulkan dari uraian di atas, yaitu :

a. Secara umum, persoalan dual earner family dalam konteks kesejahteraan psikologis anak ialah stres kerja dan waktu yang terbatas bagi anak. Ke dua hal itu merupakan sumber terbentuknya keluarga yang tidak fungsional.

b. Penelitian tentang dual earner family dalam konteks kesejahteraan psikologis anak lebih fokus pada relasi ibu dan sebagai subjek, dibanding ayah dan anak. Hal itu karena secara tradisional, ibu adalah care giver dan bukan bread winner.

c. Beberapa kondisi psikologis negatif yang dapat dialami anak dengan dual earner family, ialah : mood yang buruk, mudah marah, agresif, depresi, sikap negatif terhadap sekolah, cemas, melanggar aturan, tidak patuh, mencuri, hingga merusak properti umum.

\section{DAFTAR PUSTAKA}

Allen, T. D., Herst, D. E., Bruck, C. S. \& Sutton, M. (2000). Consequences Associated with Workto-Family Conflict: A Review and Ggenda for Future Research. Journal of Occupational Health Psychology, 5(2), 278-308.

Badan Pusat Statistik. (2013). Persentase Rumah Tangga Menurut pProvinsi, Jenis Kelamin KRT yang bekerja, dan Daerah Tempat Tinggal, 2009-2012. Diunduh dari https://www.bps.go.id/statictable/2012/04/19/1606/ pada pada tanggal 9 Oktober 2018.

Christine, W, S., Oktorina, M \& Mula, I. (2010). Pengaruh Konflik Pekerjaan dan Konflik Keluarga terhadap Kinerja dengan Konflik Pekerjaan Keluarga sebagai Intervening Variabel (Studi pada Dual Career Couple di Jabodetabek). Jurnal Manajemen dan Kewirausahaan 12(2), 121-132.

Crouter, A.C., Bumpus, M.F., Maguire, M.C., \& McHale, S.M. (1999). Linking Parents' Work Pressure and Adolescents' Well-Being: Insights into Dynamics in Dual-Earner Families. Developmental Psychology, 35(6), 1453-1461.

Davis, K.D. (2008). Daily Positive and Negative Work-Family Spillover and Crossover Between Mothers and Children. Dissertation Abstracts International: Section B: The Sciences and Engineering, 72(3-B), 1825.

Frone, M. R. (2000). Work-family Conflict and Employee Psychiatric Disorders: The National Comorbidity Survey. Journal of Applied Psychology, 85(6), 688-895. 
Harpel, C (1985). An Analysis of Dual Earner Families in Canada. Ontario : IRC Press.

Kinnunen, U. \& Mauno, S. (2001). Dual-earner Families in Finland: Differences Between and Within Families in Relation to Work and Family Experiences. Community, Work, \& Family, 4(1), 87-107.

Matjasko, J. L., \& Feldman, A. F. (2006). Bringing Work Home: The Emotional Experiences of Mothers and Fathers. Journal of Family Psychology, 20, 47-55.

Parcel, T.L., \& Menaghan, E.G. (1994). Early Parental Work, Family Social Capital, and Early Childhood Outcomes. American Journal of Sociology, 99, 972- 1009.

Piotrkowski, C.S., \& Hughes, D. (1993). Dual-Earner Families in Context: Managing Family and Work Systems. Dalam F. Walsh (Ed.). Normal Family Processes. New York: The Guilford Press.

Shimazu, A., Kubota, K., Bakker, A., Demerouti, E., Shimada, K \& Kawakami, N. (2013). Workto-family Conflict and Family-to-work Conflict among Japanese Dual-earner Couples with Preschool Children: A Spillover-Crossover Perspective. Journal of Occupational Health, 55, 234-243.

Smith, C, R. (1992). Trends and Directions in Dual-Career Family Research. Women in Management Review, 7(1), 23-28.

Stewart, W., \& Barling, J. (1996). Fathers' Work Experiences Affect Children's Behaviors via Jobrelated Affect and Parenting Behaviors. Journal of Organizational Behavior, 17, 221-232.

Tisdale, S., \& Pitt-Catsouphes, M. (2012). Linking Social Environments with The Wellbeing of Adolescents in Dual-Earner Families. Youth \& Society, 44(1), 116-138.

Unger, D.G., Brown, M.B., Tressell, P.A., \& Ellis McLeod, L. (2000). Interparental Conflict and Adolescent Depressed Mood: The Role of Family Functioning. Child Psychiatry and Human Development, $31,23-41$.

U.S. Bureau of Labor Statistics. (2006a). Employment characteristics of families in 2005 (News Release). Washington, DC: U.S. Department of Labor.

Vandewater, E.A., \& Lansford, J.E. (2005). A Family Process Model of Problem Behaviors in Adolescents. Journal of Marriage and Family, 67, 100-109.

Voydanoff, P. (2004). Work, Community, and Parenting Resources and Demands as Predictors of Adolescent Problems and Grades. Journal of Adolescent Research, 19(2), 155-173.

Wierda-Boer, H. \& Ronka, A. (2004). I Wished My Mother Enjoyed Her Work. Young, 12(4), 317-335.

Zahn-Waxler, C., Shirtcliff, E. A. \& Marceau, K. (2008). Disorders of Childhood and 121 Adolescence: Gender and Psychopathology. Annual Review of Clinical Psychology, 4, 275 303.

Zick, C. D., Bryant, K. W. \& Österbacka, E. (2001). Mother's Employment, Parental Involvement, and The Implications for Intermediate Child Outcomes. Social Science Research, 30(1), 25 49. 